*Especialista em Direito do Estado com área de concentração em Direito Tributário, Universidade Estadual de Londrina. Advogada em Maringá - PR.

**Doutor e Mestre em Direito do Estado pela Universidade Federal do Paraná. Especialista em Direito Tributário pelo Instituto Brasileiro de Estudos Tributários. Professor da graduação da PUCPR campus Londrina e das Faculdades Londrina. Professor da Pós-Graduação "lato sensu" em Direito em diversas instituições. Advogado. Membro do Instituto de Direito Tributário de Londrina - IDTL.

\section{A Tributação Extrafiscal Como Instrumento De DESENVOLVIMENTO ECONÔMICO}

\author{
The Overtaxation As An Economical Development \\ TOOL
}

Como citar: SALVADOR, Ana Carolina Garcia; CUNHA Carlos Renato da. A TRIBUTAÇÃO EXTRAFISCAL COMO INSTRUMENTO DE DESENVOLVIMENTO ECONÔMICO. Revista do Instituto de Direito Constitucional e Cidadania IDCC, Londrina, v. 4, n. 2, p 109-122, dez, 2019. ISSN: 2596-0075. https://doi.org/10.48159/revistadoidcc.v4n2.salvador.cunha

Resumo:A tributação extrafiscal não tem expressa previsão legal, porém trata-se de construção doutrinária em consonância com os princípios e regramentos implantados pela Constituição Federal de 1988. A utilização da tributação com função extrafiscal vem se mostranto um instrumento importante e eficiente para a concretização de direitos fundamentais e sociais pelo Estado, sendo utilizada para viabilizar a máxima efetivação dos citados direitos, os quais englobam os preceitos implícitos no desenvolvimento econômico, sendo, portanto, uma manifestação de intervenção do Estado na ordem econômica com o fim de viabilizar um dos fundamentos do Estado que é o desenvolvimento econômico.

Palavras-chave: Extrafiscalidade. Desenvolvimento Econômico. Intervenção na Ordem Econômica. Direitos Fundamentais e Sociais.

\begin{abstract}
The overtaxation has no express legal provision, however, it's a doctrinal constrution in line with the principles and specific regulations implemented by the Federal Constitution of 1988. The taxing utilization as extra tax function has been proved animportant and effective tool for the realization of fundamental and social rights by the State, being used to enable the full realizationof these rights, which include the principles implicit in economic development and is therefore a manifestation of state intervention in the economic order to enable one of the founda-
\end{abstract}


tions of the state which is the economic development.

Keywords: Overtaxation; Economic development; Intervention in the Economic Order; Fundamental and Social Righ. 


\section{INTRODUÇÃO}

O trabalho que ora se apresenta, objetivou examinar e explicar os contornos da utilização de tributos sob o viés da extrafiscalidade, tendo em vista que a função primordial para instituição dos tributos é a fiscal, com fim de promover a arrecadação de verbas destinadas aos cofres públicos.

A Constituição Federal, implantada em 1988, além de instituir os direitos fundamentais e sociais, atribuiu ao Estado a obrigatoriedade de assegurá-los a toda sociedade, considerando, em seu artigo $3^{\circ}$, o desenvolvimento econômico como um dos fundamentos da República Federativa.

Destaca-se, conforme será demonstrado, que, quando se fala em desenvolvimento econômico, seu conceito não está compreendido apenas pela riqueza dos indivíduos, mas engloba também o conjunto de direitos fundamentais colocados à disposição dos indivíduos, sem os quais não há como viabilizar o desenvolvimento econômico.

A princípio, verifica-se que a arrecadação realizada por meio da cobrança de tributos tem o condão de propiciar recursos para que o Estado custeie e promova suas funções nos moldes propostos pela Constituição, garantindo, assim, que a população tenha acesso aos direitos fundamentais e sociais.

Ocorre que, nem sempre as verbas arrecadadas são suficientes para promover as políticas públicas com o fim de atender as demandas do Estado, desprestigiando princípios de elevada estima na Constituição Federal.

Assim, pretende-se realizar uma breve análise sobre a utilização da função extrafiscal dos tributos com fim de viabilizar o desenvolvimento econômico nos moldes propostos pela Constituição.

Para tanto, o presente trabalho abordará, de forma sucinta, tanto o conceito de desenvolvimento econômico, quanto o conceito acerca das funções fiscais e extrafiscais dos tributos, discorrendo, por fim, sobre a possibilidade da intervenção do Estado no domínio econômico por meio da instituição de tributos de caráter extrafiscal, utilizando-se, como exemplo, a criação do Programa Universidade para Todos - PROUNI.

\section{DEFINIÇÃO DE DESEVOLVIMENTO ECONÔMICO SEGUNDO A CONSTITUIÇÃO}

A Constituição Federal em seu artigo $3^{\circ}$, inciso II, dispõe:

Art. $3^{\circ}$ Constituem objetivos fundamentais da República Federativa do Brasil:

$[\ldots]$

II - garantir o desenvolvimento nacional';

1 BRASIL. Constituição (1988). Disponível em:<http://www.planalto.gov.br/ccivil_03/Constituicao/ Constituicao.htm>. Acesso em: 06 ago. 2015. 
Assim, nota-se que cabe ao Estado garantir o desenvolvimento econômico. Desta feita, impende destacar que o desenvolvimento econômico engloba outras diretrizes do Estado também previstas na Carta Magna, dentre elas a garantia dos direitos fundamentais e sociais, sem os quais não há como se falar em desenvolvimento econômico.

Sobre este tema, interessante apresentar a concepção de desenvolvimento econômico elencado pela a Autora Carla Abrantkoski, em seu livro Direito ao Desenvolvimento, a qual analisa o instituto do desenvolvimento sob a perspectiva objetiva e subjetiva de suas relações, já indicando que o desenvolvimento deve ser idealizado juntamente com outros preceitos constitucionais:

Portanto, em princípio, vislumbramos o desenvolvimento num sentido objetivo, a ser entendido como uma utopia ou ideal a ser atingido, que pode ser deduzido das normas e dos princípios constitucionais relacionados ao desenvolvimento que deve orientar a legislação ordinária pela qual se pautarão as políticas públicas concernentes. Já, num segundo sentido, poder-se-ia formular a idéia [...] de desenvolvimento, num aspecto subjetivo, se for considerada a relação entre os agentes por ele responsáveis ou beneficiários do processo desenvolvimentista, quer no cenário internacional, quer no panorama interno. ${ }^{2}$ [grifo nosso]

Em complemento ao acima transcrito, cita-se o Doutrinador Nelson Nery Junior,

vejamos:

Desenvolvimento econômico e social. A ordem econômica está vinculada ao desenvolvimento econômico em concomitância do social. Para atingir tal desiderato, a atividade econômica por parte do Estado precisa ser planejada de maneira integrada. A atuação econômica estatal deverá ser integrada a um planejamento ambiental que racionalize o aproveitamento energético, aquático e que esteja comprometido com a preservação do meio ambiente e o desenvolvimento sustentável. A atuação econômica também precisa estar integrada à pesquisa científica e tecnológica, em que toda a orientação está voltada para a promoção do bem estar dos cidadãos. ${ }^{3}$

O economista Amartya Sen, pautado nas ideias acima, vai mais além e preconiza que o desenvolvimento econômico não pode se limitar ao aspecto puramente econômico como, por exemplo, avaliar seu alcance por meio do Produto Interno Bruto - PIB. ${ }^{4}$

Para o citado autor, em seu livro Desenvolvimento com Liberdade, o desenvolvimento econômico é avaliado de acordo com as "liberdades substantivas" conferidas às pessoas, conforme infere-se da citação abaixo:

[...] na visão normativa usada aqui, liberdades substantivas individuais são críticas. O sucesso de uma sociedade é avaliado, nesta visão, primordialmente

2 RISTER, Carla Abrantkoski. Direito ao Desenvolvimento: antecedentes, significados e consequências. Rio de Janeiro: Renovar 2007.

3 NERY JUNIOR, Nelson; NERY, Rosa Maria de Andrade. Constituição Federal Comentada e Legislação Constitucional. 2. ed. São Paulo: Revista dos Tribunais, 2009. 639 p.

4 MARQUES, Guilherme Ramon Garcia. Analisando o Desenvolvimento: a perspectiva de Amartya Sen. Revista Urutágua - academia multidisciplinar - DCS/UEM, Maringá, n. 22, set./ dez. 2010. 
pelas liberdades substantivas que os membros dessa sociedade detêm.

"O que as pessoas conseguem realizar é influenciado por oportunidades econômicas, liberdades políticas, poderes sociais e por condições habilitadoras, como boa saúde, educação básica e incentivo e aperfeiçoamento de iniciativas" "5

Ou seja, o desenvolvimento econômico somente é alcançado quando o Estado propicia às pessoas, além da riqueza, o acesso à qualidade de vida, como, por exemplo, o acesso aos direitos sociais previstos no artigo $6^{\circ}$, da Constituição Federal, dentre outros de extremada importância e destaque no citado comando legal.

Convém, aqui destacar o artigo 170 da Constituição Federal, o qual dispõe acerca dos princípios que regem a ordem econômica, in verbis:

Art. 170. A ordem econômica, fundada na valorização do trabalho humano e na livre iniciativa, tem por fim assegurar a todos existência digna, conforme os ditames da justiça social, observados os seguintes princípios:

I - soberania nacional;

II - propriedade privada;

III - função social da propriedade;

IV - livre concorrência;

$\mathrm{V}$ - defesa do consumidor;

VI - defesa do meio ambiente;

VI - defesa do meio ambiente, inclusive mediante tratamento diferenciado conforme o impacto ambiental dos produtos e serviços e de seus processos de elaboração e prestação; (Redação dada pela Emenda Constitucional $n^{\circ} 42$, de 19.12.2003)

VII - redução das desigualdades regionais e sociais;

VIII - busca do pleno emprego;

IX - tratamento favorecido para as empresas brasileiras de capital nacional de pequeno porte.

IX - tratamento favorecido para as empresas de pequeno porte constituídas sob as leis brasileiras e que tenham sua sede e administração no País. (Redação dada pela Emenda Constitucional n ${ }^{\circ}$ 6, de 1995)

Parágrafo único. É assegurado a todos o livre exercício de qualquer atividade econômica, independentemente de autorização de órgãos públicos, salvo nos casos previstos em lei. ${ }^{6}$

Da análise da própria constituição, quando de sua normatização acerca da ordem econômica, infere-se que a todos deve ser assegurada a "existência digna" norteada pela justiça social, que nada mais é do que assegurar ao cidadão as "liberdades subjetivas" segundo a teoria de desenvolvimento com liberdade de Sen, acima citada. ${ }^{7}$

Partindo deste pressuposto, Eros Grau, segundo análise realizada pela Autora Carla Abrantkoski Rister, diferencia o crescimento e o desenvolvimento econômico, sendo que o primeiro se refere ao critério quantitativo e o segundo se refere ao critério qualitativo, vejamos:

Distinguindo o mero crescimento do desenvolvimento, Eros Grau afirma que a 
idéia [Sic.] de desenvolvimento supõe dinâmicas mutações e importa em que se esteja a realizar, na sociedade por ela abrangida, um processo de mobilidade social contínuo e intermitente. O processo de desenvolvimento poderia levar a um salto, de uma estrutura social para outra, acompanhado de elevação do nível econômico e do nível cultural-intelectual comunitário. Daí por que, importando a consumação de mudanças de ordem não apenas quantitativa, mas também qualitativa, não poderia o desenvolvimento ser confundido com a idéia [Sic] de crescimento. Este último, meramente quantitativo, compreenderia uma noção de desenvolvimento. $^{8}$

Portanto, vê-se que o atendimento a um dos fundamentos da República Federativa do Brasil, qual seja o desenvolvimento nacional, não está adstrito apenas em elevar a riqueza da população, mas em viabilizar a qualidade de vida atendendo aos demais preceitos da Constituição Federal, tais como direitos fundamentais e sociais, o que, consequentemente, elevará a riqueza financeira da população que estará apta a angariar riquezas pelo seu próprio esforço.

\section{DA INTERVENÇÃO DO ESTADO NO DOMÍNIO ECONÔMICO}

Anterior à questão atinente à possibilidade de o Estado intervir ou não no domínio econômico, importante conceituar a ordem econômica.

O Autor Leonardo Vizeu Figueiredo, define a ordem econômica como sendo:

[...] o tratamento jurídico disciplinado pela Constituição para a condução da vida econômica da Nação, limitado e delineado pelas formas estabelecidas pela própria Lei Maior para legitimar a intervenção do Estado no domínio privado econômico?.

Continuando, o citado Autor, norteado pelo entendimento do ex-ministro do Supremo Tribunal Federal Eros Grau, o qual dispõe que a Constituição Federal de 1988 tratou a ordem econômica sob duas vertentes, a ampla, norteada pelo mundo do ser (ordem do fato), a qual promove a regulação normativa da atividade econômica voltada a normatizar a intervenção do Estado na economia e, uma visão mais estrita, compreendida pelo mundo do dever-ser (ordem de direito), direcionada, assim, a regular o comportamento dos agentes econômicos no mercado. ${ }^{10}$

O artigo 170, caput, da Constituição Federal, seria a expressão do ser, representando um conjunto de relações econômicas e, o artigo $173, \S 5^{\circ}$, que seria a expressão do dever-ser, seria um conjunto de normas jurídicas disciplinadoras destas relações econômicas. ${ }^{11}$

Em seu livro Lições de Direito Econômico, o autor Leonardo Vizeu Figueiredo, discorre sobre as seguintes formas econômicas de Estado: a) Estado Liberal, o qual basicamente exalta o

8 Cf. EROS GRAU apud RISTER, Carla Abratkoski, 2007.

9 FIGUEIREDO, Leonardo Vizeu. Lições de Direito Econômico. 7 ed., rev. atual. e ampl., Rio de Janeiro: Forense, 2014.

10 Cf. Ibid., p. 44.

11 Cf. Ibid., p. 70. 
princípio da livre-iniciativa, baseada na teoria de Adam Smith, modelo que seria regulado pela total liberdade do mercado; b) Estado Intervencionista Econômico, visa, primordialmente, a assegurar a livre concorrência por meio de políticas públicas intervencionistas do Estado, regular o mercado por meio da intervenção estatal, obtendo o crescimento econômico e aumentando a geraçãro de trabalho; c) Estado Intervencionista Social, já esta forma de intervenção estatal, se preocupa basicamente com a garantia o bem-estar social, onde toda a sociedade assume os ricos sociais; d) Estado Intervencionista Socialista, é norteado pela intervenção máxima onde o interesse coletivo prevalece ao interesse individual; e) Estado Regulador, este modelo seria a fundição entre o modelo de liberalismo e os modelos de intervanção social e socialista, onde o Estado intervem na economia na medida em que a constituição autoriza, visando à proteção dos direitos sociais sem, contudo, desrespeitar a livre-iniciativa e a livre-concorrência. ${ }^{12}$

Com efeito, verifica-se que o Estado brasileiro adotou o modelo de Estado Regulador, podendo intervir ordinariamente de forma indireta e, extraordinariamente, de forma direta.

Ainda sobre o tema, compiladamente, interesante se faz citar o entendimento esboçado pelo respeitado jurista Ives Grandra da Silva Martins, segue:

Toda a ordem economica está voltada a um liberalismo social ou a um socialismo liberal, que, no dizer de Miguel Reale e Oscar Corrêa, compõem a terceira via de economia moderna. Ambos autores mostram que a economia de mercado, perfilada pelo Constituinte de 1988, está temperada por valores sociais, a ponto de os dois fundamentos maiores do art. 170 referirem-se, de um lado, à valorização do trabalho humano e, de outro, à livre iniciativa, Esta última só é possível em face da livre concorrência (art. 170, inciso, IV) e está balizada por dois mecanismos de cerceamento de desvios, quais sejam, na ponta da produção e circulação de mercadorias e serviços, pelo controle do abuso do poder econômico (art. $173, \S 4^{\circ}$, da CF), e na ponta do consumo, à proteção ao direito do consumidor (5. ${ }^{\circ}$, inciso XXXII e 170 , inciso V). ${ }^{13}$

Assim, vê-se que de acordo com que preceitua o artigo 174 da Constituição Federal, o Estado brasileiro, como regulador da econômia, exerce sua atuação na economia de forma, fiscalizadora, planejadora e incentivadora, conforme infere-se de sua leitura:

Art. 174. Como agente normativo e regulador da atividade econômica, o Estado exercerá, na forma da lei, as funções de fiscalização, incentivo e planejamento, sendo este determinante para o setor público e indicativo para o setor privado.

$\S 1^{\circ}$ A lei estabelecerá as diretrizes e bases do planejamento do desenvolvimento nacional equilibrado, o qual incorporará e compatibilizará os planos nacionais e regionais de desenvolvimento.

$\S 2^{\circ}$ A lei apoiará e estimulará o cooperativismo e outras formas de associativismo. $\S 3^{\circ} \mathrm{O}$ Estado favorecerá a organização da atividade garimpeira em cooperativas, levando em conta a proteção do meio ambiente e a promoção econômico-social dos garimpeiros.

$\S 4^{\circ}$ As cooperativas a que se refere o parágrafo anterior terão prioridade na autorização ou concessão para pesquisa e lavra dos recursos e jazidas de minerais garimpáveis, nas áreas onde estejam atuando, e naquelas fixadas de acordo com o 
art. 21, XXV, na forma da lei. ${ }^{14}$

Verifica-se que havendo inconformidades no bom andamento da economia do Estado, que prejudiquem de qualquer forma o alcance dos diretos fudamentais e sociais amparados pela Constituição vigente, o Estado deverá intervir na economia promovendo sua regulação e garantindo a toda população o bem-estar social.

Marçal Justen Filho, define a regulação economica da seguinte forma:

A regulação econômico-social consiste na atividade estatal de intervenção indireta sobre a conduta dos sujeitos públicos e privados, de modo permanente e sistemático, para implementar as políticas de governo e a realização dos direitos fundamentais. ${ }^{15}$

Com efeito, nota-se que a regulação econômica pelo Estado objetiva atingir não apenas os princípios norteadores da ordem econômica, mas, principalmente, que, por meio deles, sejam atingidos os fins propostos pela Constituição, respeitando o interesse coletivo, sem, contudo, despretigiar os direitos fundamentais e sociais do indivíduo.

Assim, as "liberdades subjetivas" da teoria de $\operatorname{Sen}^{16}$ estão sendo garantidas e sopesadas na aplicação das Políticas Públicas que visam regular a economia, tendo estas liberdades peso quando da aferição do desenvolvimento nacioal como um todo.

\section{DA TRIBUTAÇÃO}

De forma simplificada, importante se faz a conceituação de tributo, explanada pelo jurista Paulo de Barros Carvalho, o qual o define do seguinte modo:

[...] tributo, em sua configuração estática, é a endonorma que apresenta como hipótese um conjunto de critérios para a identificação de fatos da realidade física, que não acordos de vontade considerados, em si mesmos, e, como consequência, um conjunto de critérios que nos permite identificar uma relação jurídica que se instaura entre o Estado (por via de regra), na qualidade de sujeito ativo e alguma pessoa física ou jurídica, na condição de sujeito passivo, mediante a qual haverá o primeiro o direito subjetivo público de exigir da segunda o cumprimento do dever jurídico consubstanciado numa prestação pecuniária. ${ }^{17}$

Assim, temos que a institução do tributo pelo ente estatal trata-se de um "acordo de vontades" onde o Estado está apto a exigir do sujeito passivo (população) uma contraprestação pecuniária, quando este último agir de acordo com os critérios pré-estabelecidos. Desta forma, uma vez enquadrado na exigência legislativa o fato realizado pelo sujeito ativo, torna legítima a cobrança de tributo pelo Estado.

A imposição e a legitimidade de exigir tributos pelo Estado não é algo que se pretende

14 BRASIL. Constituição (1988) op. cit., 2015.

15 JUSTEN FILHO, Marçal. Curso de Direito Administrativo. São Paulo: Saraiva. 2005. p. 447.

16 Cf. SEN, Amartya apud MARQUES, Guilherme Ramon Garcia, p.120-122, 2010.

17 CARVALHO, Paulo de Barros. Teoria da Norma Tributária. 5. ed. São Paulo: Quartier Latin, 2009a, p. 99. 
discutir, mas sim sua conceituação norteada pela sua finalidade.

Quanto à este tema, preliminarmente, cumpre esclarecer que a legislação é omissa em relação a conceituação da fiscalidade ou a extrafiscalidade dos tributos.

Tais classificações ficam por conta da construção doutrinária. Paulo de Barros Carvalho, bem explana sobre o tema, veja-se:

Os signos fiscalidade, extrafiscalidade e parafiscalidade são termos usualmente empregados no discurso da Ciência do Direito, para representar valores finalísticos que o legislador imprime na lei tributária, manipulando as categorias jurídicas posta a sua disposição. Raríssimas são as refêrencias que a eles faz o direito positivo, tratando-se de construções puramente doutrinárias. O modo como se dá a utilização do instrumental jurídico-tributário é o fator que identifica o gravame em uma das três clases. [grifo nosso $]^{18}$

Assim, infere-se que o fim que a norma tributária visa atingir é o que definirá sua categoria, ou seja, a classificação da norma em fiscal ou extratafiscal, como será estudada no presente trabalho não se dá de forma puramente objetiva, mas por meio da intenção implícita na norma.

Desta feita, passa-se a sua classificação.

\subsection{Da fiscalidade}

A instituição da tributação imposta pelo Estado tem como fim precípuo atingir a fiscalidade, ou seja, promover a arrecadação destinada a cumprir os fins-obrigação do Estado para com seus governados, porém nem sempre foi esta a destinação dada à arrecadação pelo Governo.

No livro intitulado A Idéia de Liberdade no Estado Patrimonial e no Estado Fiscal, do renomado Autor Ricardo Lobo Torres, em suas conclusões, explica que, na evolução do Estado Fiscal, a fiscalidade se impõe como liberdade, prevalecendo a soberania, bem como as ideias de contrato social e dando às finanças conotação de coisa pública. ${ }^{19}$

Ou seja, a tributação, nesta nova vertente, inibiu o confisco e começou a voltar seus olhos para o bem-estar social, neste sentido, cita-se trecho da obra acima referenciada: "O tributo, no Estado Fiscal, deixa de ser forma de opressão de direitos e passa a se constituir em preço da liberdade: estimula-se a riqueza da nação, adota-se a ética no trabalho, alivia-se a crítica à usura e se permite consumo suntuário." 20

Com efeito, em uma classificação mais moderna Paulo de Barros Carvalho conceitua a fiscalidade da seguinte forma:

Fala-se, assim, em fiscalidade sempre que a organização jurídica do tributo denuncie que os objetivos que presidiram sua instituição, ou que governam certos aspectos da sua estrutura, sejam voltados ao fim exclusivo de abastecer os cofres públicos, sem que os

18 CARVALHO, Paulo de Barros. Curso de Direito Tributário. 21 ed. São Paulo: Saraiva. 2009 b, p. 254. 19 Cf. TORRES, Ricardo Lobo. A Idéia de Liberdade no Estado Patrimonial e no Estado Fiscal. Rio de Janeiro: Renovar. 1991.

20 TORRES, Ricardo Lobo op. cit., p.150, 1991. 
outros interesses --- sociais, políticos ou econômicos --- interfiram no direcionamento da atividade impositiva. ${ }^{21}$

Enfim, sempre que a norma de imposição tributária visar apenas os fins arrecadatórios, voltada a angariar recursos para os cofres público, se estará diante de uma norma tipicamente fiscal.

\subsection{Da tributação extrafiscal}

Em contrapartida à tributação fiscal, tem-se a tributação extrafiscal, a qual pode ser verificada quando sua instituição visa atingir fins diversos do puramente arrecadatório.

O caráter extrafiscal da norma tributária tomou feição com a evolução dos modelos constitucionais, tal como a Constituição de 1988 que prioriza o atendimento e garantia pelo Estado aos direitos fundamentais, sociais e aos preceitos da ordem econômica incutida dos citados valores.

Anteriormente, não se impunha ao Estado esta postura ativa em relação a sua atuação, porém com suas novas atribuições se faz necessário que o Estado atue de forma mais intensa no comportamento da sociedade com fins de atingir seus objetivos. ${ }^{22}$

Paulo de Barros Carvalho dispõe que, apesar de um tributo ter sua natureza extrafiscal, não quer dizer que ele deixou de exercer sua função arrecadatória, porém, o fim primordial é promover algum direito fundamental em detrimento ao seu fim precípuo que é o arrecadatório, veja-se:

Há tributos que se prestam, admiravelmente, para introdução de expedientes extrafiscais. Outros, no entanto, inclinam-se mais no setor da fiscalidade. Não existe, porém, entidade tributária que se possa dizer pura no sentido de realizar tão-só a fiscalidade, ou, unicamente a extrafiscalidade. Os dois objetivos convivem harmônicos, na mesma figura impositiva, sendo apenas lícito verificar que, por vezes um predomina sobre o outro. ${ }^{23}$

O mesmo Autor exemplifica alguns tributos que materializam a atuação extrafiscal do Estado, entre eles, tem-se o Imposto Territorial Rural, que, de acordo com a destinação do imóvel incide sua exação de forma mais gravosa, visando em primeiro plano a atender primordialmente as finalidades da ordem econômica e social, porém sem excluir o cunho arrecadatório. ${ }^{24}$

Dessa forma, vê-se que a norma extrafiscal não precisa ser exclusivamente de caráter extrafiscal, neste sentido o renomado jurista José Cassalta Nabais, explica:

Assim, manifesta-se a extrafiscalidade, que pode ser compreendida como aquelas normas que, embora façam parte do direito fiscal, não tem por finalidade

21 CARVALHO, Paulo de Barros op.cit., p.254-255, $2009 b$.

22 CALENDO, Paulo. A Extrafiscalidade como Instrumento de Implementação dos Direitos Fundamentais e Sociais no Brasil. Revista Jurídica do Cesuca, Cachoeirinha, v.2, n. 4, 62 p. dez/2014.

23 CARVALHO, Paulo de Barros op. cit., p. 256, 2009 b.

24 Cf. Ibid., p. 255. 
dominante a consecução de receitas para o Estado, mas objetivam realizar determinada finalidade econômica ou social. ${ }^{25}$

Portanto, objetivando a proteção dos direitos amparados pela Constituição Federal, em especial os direitos fundamentais e sociais, o Estado é legitimado a instituir, majorar ou conceder imunidades tributárias, não apenas adstrito à sua finalidade arrecadatória, mas objetivando também à finalidade extrafiscal da norma tributária.

\section{DA UTILIZAÇÃO DA TRIBUTAÇÃO EXTRAFISCAL COMO MEIO DE INTERVENÇÃO NO DOMÍNIO ECONÔMICO COM O FIM DE VIABILIZAR O DESENVOLVIMENTO ECONÔMICO}

Sobre a possibilidade de intervenção do Estado no domínio econômico, no item 3 do presente trabalho, ficou demonstrado que a Constituição de 1988, em seu artigo 174, viabiliza que o Estado intervenha no domínio econômico para regular a ordem econômica.

Da leitura do referido artigo, infere-se que cabe ao Estado, como agente normativo e regulador da atividade econômica, cumprir tal fim por meio das funções de fiscalização, incentivo e planejamento.

Sobre o tema, Kiyoshi Harada, em seu livro Direito Financeiro e Tributário, assim dispõe:

De fato, o Estado intervém na atividade econômica por meio de seu poder normativo, elaborando leis de combate ao abuso poder econômico, de proteção consumidor, leis tributárias de natureza extrafiscal conferindo-lhes caráter ordinatório etc. ${ }^{26}$

Assim, quando o Estado atribui à norma tributária o caráter extrafiscal, ele está promovendo a intervenção por meio de incentivo, quer seja majorando um tributo, quer seja minorando, de acordo com a intenção de estimular ou inibir alguma conduta praticada pelo contribuinte, para, enfim, resguardar algum preceito constitucional.

Também, de acordo com o explanado nos tópicos acima, a ordem econômica é composta não apenas por indicativos de riquezas, mas sim pela qualidade de vida do indivíduo, ou seja, a ordem econômica é composta pelo desenvolvimento econômico e social ${ }^{27}$, os quais devem primar pela garantia dos direitos fundamentais correlatos os quais o Estado está obrigado a garantir, conforme se infere do artigo $3^{\circ}$, inciso II, da Constituição Federal entre outros já citados de igual importância.

Desta feita, pode-se destacar como forma de exemplificação da atuação extrafiscal do Estado, a criação da Lei 11.096/05 que instituiu o Programa Universidade para Todos - PROUNI, o qual visa resguardar o direito fundamental social à educação.

25 NABAIS, José Cassalta. O Dever Fundamental de Pagar Impostos. Coimbra: Almedina, 1998.

26 HARADA, Kiyoshi. Direito Financeiro e Tributário. 18. ed. rev. e ampl. São Paulo: Atlas, 2009 , p. 8.

27 Cf. NERY JUNIOR, Nelson; NERY, Rosa Maria de Andrade op. cit., p. 639, 2009. 
Em linhas gerais, o referido programa visa garantir aos estudantes de baixa renda o acesso à educação de ensino superior, concedendo às instituições que aderirem ao programa, em contrapartida, benefícios de ordem fiscal.

$\mathrm{O}$ artigo $8^{\circ}$, da citada lei, prevê isenções para as instituições que aderirem ao programa, na proporção da efetiva ocupação das bolsas devidas ( $\left(3^{\circ}\right.$, art. $8^{\circ}$, Lei 11.096/05), sendo que os tributos dos quais as referidas instituições restam isentas são: Imposto de Renda das Pessoas Jurídicas, Contribuição Social Sobre o Lucro Líquido, Contribuição Social para Financiamento da Seguridade Social e Contribuição para o programa de Integração Social.

Com efeito, dentre os tributos acima citados merece destaque o Imposto de Renda das Pessoas Jurídicas, que é conhecido por todos pelo seu caráter eminentemente fiscal e, no caso da legislação do PROUNI, tem como sua destinação principal a função extrafiscal, onde o Estado, objetivando o cumprimento de um direito social e com fins de viabilizar o desenvolvimento econômico, deixa de arrecadar para os cofres públicos para conceder ao contribuinte benefícios que o estimulem a cumprir o dever de educação do Estado. ${ }^{28}$

A citação abaixo relata muito bem o status atual da importância da utilização de tributos com o fim extrafiscal:

Felizmente, o fenômeno da utilização extrafiscal dos tributos tem se demonstrado cada vez mais presente em nosso ordenamento jurídico, materializando-se como um instrumento de efetivação do desenvolvimento econômico e social. Desse modo, defende-se que o Direito Tributário encontra, através de uma otimização da extrafiscalidade, um dos melhores instrumentos como um instrumento para implementação dos valores contemplados pela Constituição Federal de $1988 .{ }^{29}$

Assim, vê-se que a intervenção estatal por meio da utilização da função extrafiscal da norma tributária é um instrumento importante de concretização do desenvolvimento econômico, o qual torna possível o cumprimento de obrigações fundamentais do Estado. O que se visa não é o fim arrecadatório da norma tributária, mas sim a efetivação de direitos elevados pela Constituição, direitos sem os quais resta prejudicado a concretização de um dos fundamentos da Republica Federativa do Brasil que é o desenvolvimento econômico.

\section{CONCLUSÃO}

Este estudo teve como objetivo tratar sobre a utilização da função extrafiscal dos tributos como meio de indução e estímulo ao desenvolvimento econômico.

28 Cf. KALIL, GILBERTO ALEXANDRE; GONÇALVES, Oksandro Osdival. PROUNI - Estudo Preliminar Sobre a Eficiência a Partir da Análise Econômica do Direito. In: XXIV Encontro Nacional do CONPEDI, 2015, Aracaju. Anais...

29 MENDONÇA, Maris Lírida Calou de Carvalho e; ALMEIDA, Saulo Nunes de Carvalho. A Extrafiscalidade Tributária como Mecanismo de Concretização do Direito Fundamental à Educação. Pensar, Fortaleza, v. 16, n. 2, p. 678-704, jul./dez. 2011, p.687. 
No decorrer do presente trabalho, verificou-se que o bom desenvolvimento econômico não deve ser medido única e exclusivamente pelas riquezas dos indivíduos, pelo PIB de um país, mas sim pelo conjunto de direitos e garantias que o Estado disponibiliza e oferece aos indivíduos.

Foi destacado, em especial, a instituição da lei 11.096/05 que criou o Programa Universidade para Todos - PROUNI, o qual viabiliza a efetivação do direito fundamental social à educação, vez que coloca à disposição dos estudantes de baixa renda a oportunidade de cursar ensino superior, oferecendo, para tanto, bolsas integrais ou parciais.

Conforme exposto, somente é possível a disponibilização de estudo superior a uma parcela maior da população, porque o governo, por meio de incentivos fiscais, tornou interessante que instituições privadas, com ou sem fins lucrativos, cumpram a missão do Estado e deem aos indivíduos acesso à educação superior.

Ou seja, por meio da utilização da norma tributária, em sua função extrafiscal, foi possível o Estado intervir no domínio econômico e cumprir suas obrigações, efetivando, desta forma, um dos princípios fundamentais sociais que é o da educação, o qual tem grande peso para o bom desenvolvimento econômico de um país.

Como observado, a utilização da função extrafiscal do tributo visa atingir um bem maior do que a simples arrecadação aos cofres públicos, vez que, por meio de sua prática, o governo torna possível a efetivação de um direito fundamental ou social amparado pela Constituição Federal.

Assim, na prática, vê-se que a efetivação dos direitos fundamentais e sociais deve se sobressair a qualquer outro direito, bem como que a utilização da função extrafiscal se impõe quando utilizada visando o atendimento as normas constitucionais, realizando, desta forma, também a efetivação dos fundamentos e princípios norteadores da Republica Federativa do Brasil.

\section{REFERÊNCIAS}

BRASIL. Constituição (1988). Disponível em:<http://www.planalto.gov.br/ccivil_03/ constituicao/constituicao.htm>. Acesso em: 06 ago. 2015.

CALENDO, Paulo. A Extrafiscalidade como Instrumento de Implementação dos Direitos Fundamentais e Sociais no Brasil. Revista Jurídica do Cesuca, Cachoeirinha, v.2, n. 4, dez./2014.

CARVALHO, Paulo de Barros. Teoria da Norma Tributária. 5. ed. São Paulo: Quartier Latin. 2009a. 
CARVAlHO, Paulo de Barros. Curso de Direito Tributário. 21. ed. São Paulo: Saraiva. 2009b.

FIGUEIREDO, Leonardo Vizeu . Lições de Direito Econômico. 7. ed., rev. atual e ampl., Rio de Janeiro: Forense, 2014.

HARADA, Kiyoshi. Direito Financeiro e Tributário. 18. ed. rev. e ampl. São Paulo: Atlas, 2009.

JUSTEN FILHO, Marçal. Curso de Direito Administrativo. São Paulo: Saraiva. 2005.

MARQUES, Guilherme Ramon Garcia. Analisando o desenvolvimento: a perspectiva de Amartya Sen. Revista Urutágua - academia multidisciplinar - DCS/UEM. Maringá, n. 22, 120-123, set./dez. 2010.

MARTINS, Ives Grandra da Silva (Coor.) Contribuições de Intervenção no Domínio Econômico. São Paulo: Revista dos Tribunais, 2002.

MENDONÇA, Maris Lírida Calou de Carvalho e; ALMEIDA, Saulo Nunes de Carvalho. A Extrafiscalidade Tributária como Mecanismo de Concretização do Direito Fundamental à Educação. Pensar, Fortaleza, v. 16, n. 2, p. 678-704, jul./dez. 2011.

NABAIS, José Cassalta. O Dever Fundamental de Pagar Impostos. Coimbra: Almedina, 1998.

NERY JUNIOR, Nelson; NERY, Rosa Maria de Andrade. Constituição Federal Comentada e Legislação Constitucional. 2. ed. São Paulo: Revista dos Tribunais, 2009.

RISTER, Carla Abrantkoski. Direito ao Desenvolvimento: Antecedentes, Significados e Consequências. Rio de janeiro: Renovar, 2007.

TORRES, Ricardo Lobo. A Idéia de Liberdade no Estado Patrimonial e no Estado Fiscal. Rio de Janeiro: Renovar. 1991.

Recebido em: 23/10/2019.

Aprovado em: 30/11/2019. 